Int. Agrophys., 2019, 33, 271-276

INTERNATIONAL

\title{
Effect of shallow subsurface flow pathway networks on corn yield spatial variation under different weather and nutrient management
}

\author{
Billie J. Morgan ${ }^{1}$, Craig S.T. Daughtry ${ }^{2}$,Andrew L. Russ ${ }^{2}$, Waine P. Dulaney ${ }^{2}$, Timothy J. Gish ${ }^{2}$, \\ and Yakov A. Pachepsky ${ }^{1 *}$ \\ ${ }^{1}$ USDA-ARS Environmental Microbial and Food Safety Laboratory, Beltsville, MD, USA \\ ${ }^{2}$ USDA-ARS Hydrology and Remote Sensing Laboratory, Beltsville, MD, USA
}

Received December 9, 2018; accepted April 23, 2019

\begin{abstract}
Ground water availability can be a major spatially variable factor of crop yields. In soils with the infiltration-restricting layer, ground water can be organized in the network of channels that conduct water laterally in wet periods and become water storage and water subsidy sources for plants in dry periods. The objective of this work was to quantify the relationships between the distances to the subsurface flow pathway network and corn yield for different weather conditions and nutrient management. Corn yield was monitored across the manured and chemically fertilized fields at the USDA-ARS OPE3 experimental site in Maryland. Data were collected during dry, normal, and above normal years in terms of the amount of precipitation from planting to physiological maturity. The subsurface flow pathway network was delineated using ArcGIS from data on topography of the infiltration-restricting layer found mostly at depths between one and three meters. The geographically weighted regression was used. Adjusted determination coefficients of regressions ranged from 0.485 to 0.655 . Decrease of the adjusted determination coefficients from a dry to normal year and an increase from the normal to wet year was found. Factoring the subsurface flow pathway network influence into crop management can be an important component of precision farming strategies.

Keywords: subsurface flow pathways, ground penetrating radar, geographic weighted regression, corn yield
\end{abstract}

\section{INTRODUCTION}

Variability of crop yield within fields receiving the same management has long been a target of precision agriculture. Availability of water, radiation, and nutrients,

*Corresponding author e-mail: yakov.pachepsky@ars.usda.gov as well as pressure from weeds and diseases may significantly vary across crop fields, a variation in yields follows. Understanding spatial patterns of crop variability factors appears to be necessary to use resources efficiently and to improve the resilience of the farm enterprise Ground water availability can be a major spatially variable factor of crop yields. It was shown for corn that ground water depth less than one meter negatively affects yields, whereas higher yields have been recorded at intermediate (1-3 m) water table depths (Kahlown et al., 2005; Zipper et al., 2015). The portion of total seasonal evapotranspiration supplied from shallow ground water was strongly affected by water-table depth in the work of Kalita et al. (1993).

The spatial organization of shallow ground water depth is difficult to observe. Yoder et al. (2001) and Gish et al. (2002) applied ground penetration radar (GPR) and electromagnetic induction surveys at fields with loess and fluvial soils. They concluded that there exists a network of subsurface flow pathways, providing the major lateral flow of subsurface water, that are perched on a layer that restricts vertical flow. Their conceptual model was similar to the model developed in the research of lateral flow at the soil-bedrock interface. In particular, Tromp-Van Meerveld and McDonnell (2006) described the threshold-dependent occurrence of subsurface lateral flow as a "fill and spill" process, in which water ponding at the soil-bedrock interface overfilled bedrock depressions, causing water to "spill" 
downslope over the bedrock surface (Hardie et al., 2001). The spills caused the water movement through a subsurface network of narrow flow paths for the "channelized" saturated flow. As soil water contents increased, more connections between subsurface ponded areas became active. Location of the dynamic subsurface ponds was proposed to be obtained from the topography of the restricting layer, which in turn was inferred from spatially dense ground penetration radar data (Gish et al., 2002, Zhu and Lin, 2009).

Weather and nutrient management could alter the effect of the subsurface flow pathway network (SFPN) on spatial variation in crop development and yield. In dry years, there should be more time periods when plants above the flow pathway can receive ground water subsidy, whereas plants that are further from the pathways would be in less favorable conditions. This was demonstrated in the study of Walthall et al. (2004), who determined the normalized difference vegetation index (NDVI) for corn fields, where subsurface preferential flow pathways were delineated, had higher NDVI values in the proximity of the pathways themselves. The efficiency of nutrients can depend on the nutrients mobility and soil water contents, which should be different at different distances from the subsurface flow pathway network. Currently, information on the effect of subsurface flow on yields remains scarce.

The objective of this work was to estimate and compare effects of subsurface preferential lateral flow pathways on spatial variation in corn yields, with different nutrient management, in years of different water availability. The weighted geographical regression was applied to quantify the effect of the distance to subsurface pathways on the yields.

\section{MATERIALS AND METHODS}

The study site is located at the USDA-ARS Henry A. Wallace Beltsville Agricultural Research Center, MD (near $39^{\circ} 01^{\prime} 44^{\prime \prime} \mathrm{N}, 76^{\circ} 50^{\prime} 46^{\prime \prime} \mathrm{W}$ ). The 21 ha site is part of the Optimizing Production inputs for Economic and Environmental Enhancement (OPE3) study and contains four fields that range in size from 3.6 to 4.2 ha. Each field delimited by earthen berms and drains into a first-order stream and riparian wetland. The soils are variable, but the majority are coarse-loamy, siliceous, mesic typic hapludults. Surface soil textures range from sandy loams to loamy sands. Surface slopes vary between 1 and 4\%. Depth of the first continuous clay lens, identified using groundpenetrating radar (GPR), ranged from 1 to $3 \mathrm{~m}$ (Gish et al., 2002, 2005).

Corn (Zea mays L.) was planted on 17 April 2002, 18 May 2004, and 29 April 2006. It was fertilized using split applications of $\mathrm{N}$, as recommended by the University of Maryland. Field A also received uniform applications of bovine manure that was applied to the soil surface and incorporated prior to planting. To account for $\mathrm{N}$ loss, due to ammonia volatilization, additional $\mathrm{N}$ fertilizer was applied $\left(\sim 50 \mathrm{~kg} \mathrm{~N} \mathrm{ha}^{-1}\right)$ as needed at 4-5 weeks after planting, based on the pre-side dress nitrate test. Field $\mathrm{B}$ received $34 \mathrm{~kg} \mathrm{~N} \mathrm{ha}^{-1}$ at planting, plus an additional uniform application of $\mathrm{N}$ fertilizer with the rate based on the mean PSNT value. Corn grain yields were acquired with a harvester equipped with a yield monitor and a differential GPS. Measurement errors resulting from the harvester detouring around obstacles in the fields (e.g., soil moisture sensors, sampling wells, and the weather station tower) were removed from the yield data. The weather station, located in Field B, recorded solar radiation, air temperature, wind speed, and precipitation.

The SFPN were obtained using the 'stream delineation' tool, from the ArcMap hydrology tool set (Jenson and Domingue, 1988). The input for this tool was the raster of the digital elevation model (DEM) of the restrictive layer, which was obtained by subtracting krigged depth to the restrictive layer from the elevations of the land surface. The depths and elevations were obtained from ground penetration radar and kinematic GPS surveys, respectively (Gish et al., 2005). This DEM of the restrictive layer was used in the 'flow direction' tool, in ArcMap, which generated a raster showing the direction of flow out of each cell. Next, the 'flow accumulation tool' was used which represented the accumulated flow as the accumulated number of all cells flowing into each downslope cell. Different flow accumulation thresholds (FATs) can be applied to select only those subsurface flow pathway networks that have a number of inflowing cells greater than the threshold. Each delineated subsurface pathway was then converted to a feature using the 'stream to feature' tool.

Geographically weighted regression (GWR) is a spatial regression technique increasingly used in spatial dataset analysis. GWR provides a local linear regression model, that accounts for the distance between locations where independent and dependent variables are measured. These distances are used to create geographical weights for the values of the independent variable (Fotherinham et al., 2003). Weights decrease as the distances increase. The function that relates weights to distances is called kernel. Two types of kernels - fixed and adaptive - are implemented in ArcGIS. We used a fixed kernel, which was preferable, since our data points were regularly distributed rather than clustered, as Moran's I statistics showed (Charlton and Fotherinham, 2009). The size of the area, where data for GWR are collected, is controlled by the single parameter of the function kernel. This parameter, called bandwidth, is found automatically, to provide the minimum of the value of the corrected Akaike information criterion (AICc), which in turn characterizes the accuracy of the GWR estimates. The adjusted determination coefficient, $\mathrm{R}^{2}$, was utilized to assess the performance of the GWR.

The GWR was ran using yield as the dependent variable, and values of the distance, from the yield data location to the closest portion of the SFPN, were used as the predictor 
variable. The 'near' tool, in ArcMap, was used on each field yield data, for each year, for various FATs. The tool created values of the distances, which were used in GWR.

\section{RESULTS}

Cumulative precipitation was calculated for each year, for the period from planting to physiological maturity of the crop (Fig. 1). The highest cumulative precipitation $(387 \mathrm{~mm})$ was recorded in 2006 and the least precipitation $(110 \mathrm{~mm})$ in 2002. Precipitation in 2004 was $(377 \mathrm{~mm})$ near the 10- year average. The growing period in 2004 was much longer than in 2006, and the average amount of precipitation per day of the growing season was substantially larger in 2006 compared with 2004. Cumulative probability distributions, for each year and field, are shown in Fig. 2. Both weather and crop management were significant factors. Average yields were 4795, 7720, and $8724 \mathrm{~kg} \mathrm{ha}^{-1}$ at the field A and 3998, 7469, and $7983 \mathrm{~kg} \mathrm{ha}^{-1}$ at the field B in 2002, 2004, and 2006, respectively. The 2004 weather conditions caused the shape of the yield distributions to be qualitatively different from other years. In this year, a relatively large proportion of field area had very low yields. No yield was recorded at about $5 \%$ of field area.

Subsurface flow pathway networks formed branching structures. An example of such structures are shown in Fig. 3. As the FAT increases, the branches become short-

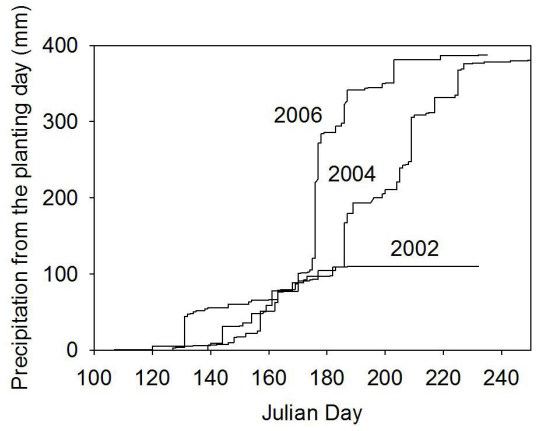

Fig. 1. Cumulative precipitation during corn crop vegetation period in 2002, 2004 and 2006. er. The pathways tended to be denser in lower parts of the fields. Densities of the flow pathways were computed as ratios of total length per unit area of the fields; units were $\mathrm{m}^{-1}$. The densities depended on the flow accumulation threshold. The dependencies followed the inverse power law (Fig. 4). The flow pathways density decreased with the increase of FAT values. The decrease was slightly faster at field B compared with field A. By and large, both fields had similar densities for the same values of the FAT (Fig. 4). As the FAT increases, inspection of the dependencies, shown in Fig. 4, suggested that FAT values 2, 8, and 21 would provide a clear representation of the differences in SFPN density.

Adjusted determination coefficients of GWR, relating yields to the distances from the subsurface flow pathway networks, are collected in Table 1. Increase in the FAT caused the decrease in determination coefficients. At low FATs the determination coefficients were relatively high - from 0.48 to 0.65 - and demonstrated the substantial influence of the presence of subsurface flow pathway networks on the yields. The increase in FAT values led to lower determination coefficients (Table 1).

The strength of relationships, between yields and distances to the SFPN, reflected the wetness of the year (Table 1). For the manured field $\mathrm{A}$, the largest $\mathrm{R}^{2}$ were obtained in dry 2002, (except FAT 21). For the standard fertilizer application field $\mathrm{B}$, the largest $\mathrm{R}^{2}$ were found in 2006. For both fields the smallest determination coefficients were found in the normal year, 2004.

For given weather conditions, the strength of the 'yield - SFPN density relationship' reflected the nutrient management practice (Table 1). In dry 2002, determination coefficients decreased in the sequence 'manure - standard,' The opposite was observed in normal and wet years 2004 and 2006, when the determination coefficients decreased in the sequence 'standard application - manure.'

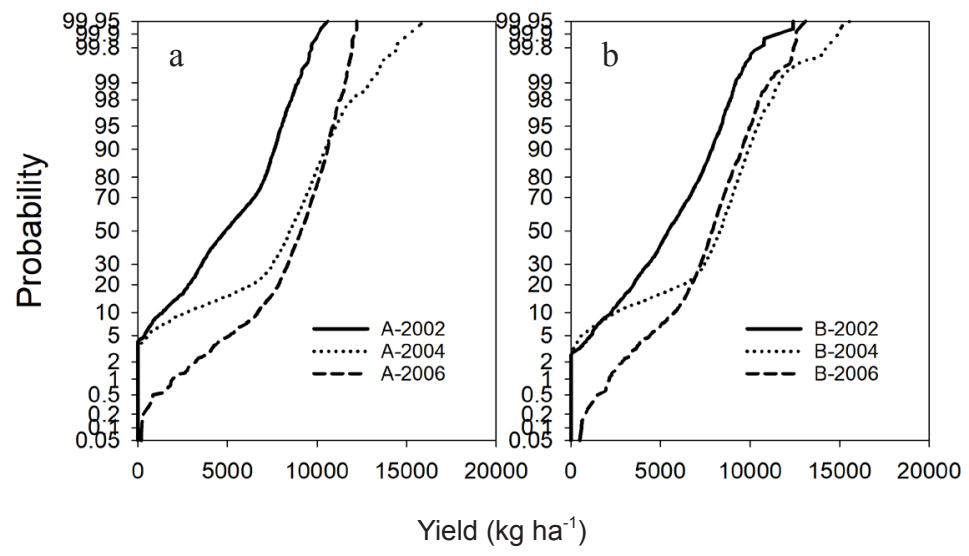

Fig. 2. Cumulative probability distributions of yield values for the observation year across: $a-$ field A, b - field B. 


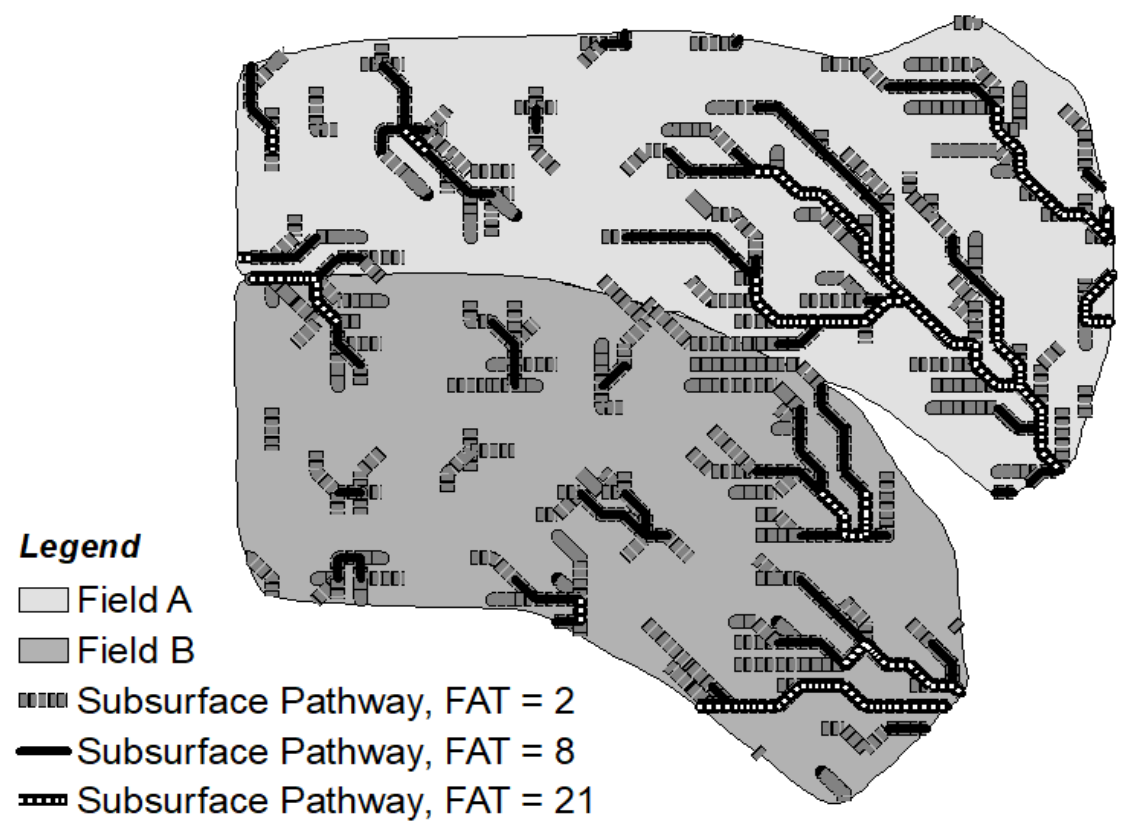

Fig. 3. Effect of the flow accumulation threshold (FAT) on the delineation of the subsurface flow pathway networks (SFPNs).

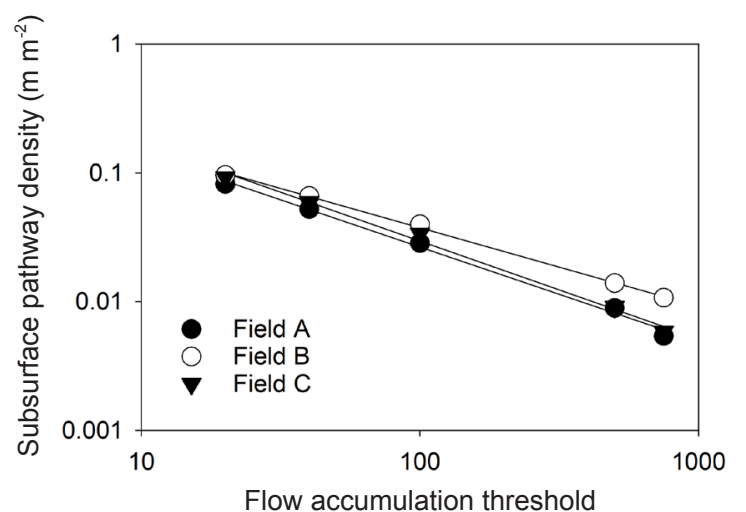

Fig. 4. Dependence of the density of subsurface flow pathway networks (SFPN) on the flow accumulation threshold (FAT).

\section{DISCUSSION}

The GWR determination coefficients were highly significant at all years and fields. This supports the idea of a close relation between the distance to the SFPN and yield. The effect of the weather on the strength of the 'yield-SFPN' relationship depended on the nutrient management. At the manured field A, coefficients were higher in drought year 2002 and became progressively smaller as years grew wetter. This trend supports the assumption of the water in SFPN segments as a source of water subsidy, i.e. availability of additional water for transpiration from shallow ground water (Lowry and Loheide, 2010). At fields with the standard fertilizer application, the determination coefficients increased from the drought year, 2002, to the wet year, 2006. A hypothetic explanation for that, is improved

Table 1. Adjusted determination coefficients of geographically weighted regressions 'distance to subsurface flow pathway network vs. corn yield'

\begin{tabular}{cccccc}
\hline \multirow{2}{*}{ Field } & Year & Growing & \multicolumn{2}{c}{ FAT } \\
\cline { 4 - 6 } & & season & 2 & 8 & 21 \\
\hline A & 2002 & Dry & 0.642 & 0.655 & 0.557 \\
A & 2004 & Normal & 0.505 & 0.482 & 0.348 \\
A & 2006 & Wet & 0.556 & 0.558 & 0.501 \\
B & 2002 & Dry & 0.576 & 0.580 & 0.427 \\
B & 2004 & Normal & 0.526 & 0.538 & 0.398 \\
B & 2006 & Wet & 0.584 & 0.592 & 0.477 \\
\hline
\end{tabular}


mobility and delivery of chemical fertilizers in the vicinity of SFPN, where the chemical transport can occur both in saturated and unsaturated conditions of capillary fringe. Substantial lateral transport of solutes in soils was demonstrated (Logsdon, 2007 for review and example). Kung et al. (2000) and Gish et al. (2004) observed chemical transit time decreases as soil water content increases. Kung and Donohue (1991) reported that solution volumes and chemical concentrations were more than $400 \%$ larger in the subsurface depression areas identified with GPR.

There may be several reasons why the GWR $\mathrm{R}^{2}$ are only moderately high. First, the procedure of localization of SFPN does not provide the information about the water storage in specific pathway segments. Therefore, the closest segment is not necessarily the most important source of water subsidy. Second, there are unavoidable errors in the pathways location that are related to the noise in GPR data. Zhang et al. (2014) demonstrated that this noise increases as the water contents increase, i.e. one has relatively higher noise closer to the pathway segment. Third, it is probably not accurate to assume that water from a SFPN is constantly available based on the plants demand during the whole vegetation period. Data in Fig. 1 show that precipitation events bring large amounts of water, but occur relatively rarely during the growing season. Therefore, periods should occur when soil water is available all over the field and when even the deepest pathways do not contain water because of a long drought. Influence of SFPNs on crop yields will depend on the duration of these periods and the growth stage of plants during these periods. Finally, the method, used in this and Gish et al. (2005) papers, relies on the FAT parameter. This parameter determines how many grid cells must drain into a cell for it to be designate as part of an SFPN location. This parameter does not quantitatively define what the actual volume of water is in a specific cell (or in neighboring cells). Therefor the distance to SFPN, per se, may not be the only useful predictor of yields.

As soon as the DEM, of the restrictive layer, is determined from GPR data with spatial analysis tools, methods other than GWR can be applied to research the relationship between crop yields and SFPNs. These various statistics will characterize this relationship. Gish et al. (2005) utilized 0 to 5,5 to 10 , and 10 to $15 \mathrm{~m}$ buffers around the subsurface pathways, to determine the strength of the influence of the pathways on corn yield. They used the same GPR dataset and ArcGIS tools as we did in this work, applied block kriging to 1998, 1999, and 2000 yield data, at two scales, and estimated yields, within the buffer bands that covered $85 \%$ of the field. The 'yield-SFPN' relationship, based on the listedbuffers, was demonstrated to be strongly dependent on the distance to the SFPN itself at $85 \%$ of the field area. Yet another analysis type suggested by Gish et al. (2005) consisted in relating the depth to the restrictive layer to yields. These authors found a well-defined parabolic relationship between yields and depths for two dry years (1998 and 1997). Other data analysis approaches may rely on the ground water flow within the network, which is not defined solely by the two-dimensional representation of the network via the number of cells draining to each other. The quantitative information about flow transport in SFPN provides more information about ground water subsidies across the field.

It is difficult to define exactly the resolution of the SFPN that provides better predictions (Table 1). Networks built from cell draining a large number of other cells $(\mathrm{FAT}=21)$, do not contain enough information to establish a relationship between yields and distance to pathways. The SFPN segments are simply too rare to affect large number of cells. The decrease of the FAT and the corresponding increase in the density of subsurface pathway networks creates better coverage of the fields (Figs 3,4) and therefore provides more information to analyze the 'yield-SFPN' relationship. However, the increase of the network density can potentially include network segments with low water storage and therefore lead to some questionable conclusions about the 'yield-SFPN' relationship.

We realize that comparison of the nutrient management effect on 'yield-SFPN' relationship is not accurate, since the subsurface flow pathway networks can be different across fields A and B. We estimated several metrics of the networks. Dependencies of pathway length, per unit area, on the cumulative flow threshold were similar for the two fields (Fig. 4).

The effect of close subsurface pathways on yield is probably not limited to the water subsidy.

Since plants close to SFPN segments experience better development year after year, soil structure and root residues should eventually become more favorable for both plant development and yield. This aspect of the pathways presence may constitute an interesting avenue of research. Modeling study of Soylu et al. (2014) indicated that the impact of ground water on surface energy and water balances could be more important than previously recognized. These authors demonstrated that corn plant phenology, emergence, and root development can be substantially altered by shallow ground water.

Shallow ground water or perched water above the restrictive layer may strongly affect the spatial distribution of crop yields. When such ground water fills a network of channels, the information, from such channels, can be a useful component of the knowledge about the crop yield variability sources.

\section{CONCLUSIONS}

1. Digital elevation model of the shallow infiltrationrestricting layer was developed for two adjacent fields using the ground penetration radar survey and high-resolution DEM of soil surface. 
2. Subsurface flow pathways were delineated from this DEM using the ArcGIS hydrologic algorithms.

3. Application of the geographically weighted regression revealed relatively strong $\left(0.505 \leq \mathrm{R}^{2} \leq 0.642\right)$ relationships between corn yield and distances to subsurface flow pathways.

4. Compared with the normal precipitation year, the relationships were stronger in the wetyear, when the subsurface pathways could prevent overwetting, and in the dry year when the pathways could serve as a temporary water storage and.

Conflict of interest: The Authors do not declare conflict of interest.

\section{REFERENCES}

Charlton M. and Fotheringham A.S., 2009. Geographically Weighted Regression. A Tutorial on using GWR in ArcGIS 9.3. National Centre for Geocomputation, National University of Ireland. Maynooth, Ireland. Available at: https://www.arcgis.com/home/item.html?id=9ae34ee00c61 4d10ab086bcb1cce9482

Fotheringham A.S., Brunsdon C., and Charlton M., 2003. Geographically weighted regression: the analysis of spatially varying relationships. John Wiley and Sons. https://doi.org/10.1111/j.1538-4632.2003.tb01114.x

Gish T.J., Dulaney W.P., Kung K.J., Daughtry C.S.T., Doolittle J. A., and Miller P.T., 2002. Evaluating use of groundpenetrating radar for identifying subsurface flow pathways. Soil Sci. Soc. Am. J., 66(5), 1620-1629.

https://doi.org/10.2136/sssaj2002.1620

Gish T.J., Daughtry C.S.T., Walthall C.L., and Kung K.J.S., 2004. Quantifying impact of hydrology on corn grain yield using ground-penetrating radar. Paper presented at the Proc. 10th Int. Conf. Ground Penetrating Radar, GPR 2004, 2 493-496.

Gish T.J., Walthall C.L., Daughtry C.S.T., and Kung K.S., 2005. Landscape and watershed processes: Using soil moisture and spatial yield patterns to identify subsurface flow pathways. J. Environ. Quality, 34(1), 274-286.

Hardie M.A., Doyle R.B., Cotching W.E., and Lisson S., 2012. Subsurface lateral flow in texture- contrast duplex soils and catchments with shallow bedrock. Appl. Environ. Soil Sci., 2012, Article ID 861358, 10 pages https://doi.org/10.1155/2012/861358

Jenson S.K. and Domingue J.O., 1988. Extracting topographic structure from digital elevation data for geographic information system analysis. Photogrammetric Engineering and Remote Sensing, 54(11), 1593-1600.

Kahlown M.A. and Ashraf M., 2005. Effect of shallow groundwater table on crop water requirements and crop yields. Agric. Water Manag., 76(1), 24-35.

https://doi.org/10.1016/j.agwat.2005.01.005
Kalita P.K. and Kanwar R.S., 1993. Effect of water-table management practices on the transport of nitrate- $\mathrm{N}$ to shallow groundwater. Trans. ASAE, 36(2), 413-422. https://doi.org/10.13031/2013.28353

Kung K-J.S., Steenhuis T.S., Gish T., Kladivko E., Bubenzer G., and Helling C.S., 2000. Impact of preferential flow on the transport of adsorptive and non-adsorptive tracers. Soil Sci. Soc. Am. J., 64, 1290-1296.

Kung K.J. and Donohue S.V., 1991. Improved solute-sampling protocol in a sandy vadose zone using ground-penetrating radar. Soil Sci. Soc. America J., 55(6), 1543-1545.

Logsdon S.D., 2007. Subsurface lateral transport in glacial till soils. Trans. ASABE, 50(3), 875-883. https://doi.org/10.13031/2013.23152

Lowry C.S. and Loheide I.I.S.P., 2010. Groundwater-dependent vegetation: quantifying the groundwater subsidy. Water Resour. Res., 46, W06202. https://doi.org/10.1029/2009wr008874

Soylu M.E., Kucharik C.J., and Loheide S.P., 2014. Influence of groundwater on plant water use and productivity: development of an integrated ecosystem-variably saturated soil water flow model. Agric. Forest Meteorol., 189, 198-210. https://doi.org/10.1016/j.agrformet.2014.01.019

Tromp-van Meerveld H.J., and McDonnell J.J., 2006. Threshold relations in subsurface stormflow: 2 . The fill and spill hypothesis. Water Resour. Res., 42, 2. https://doi.org/10.1029/2004wr003800

Walthall C.L., Gish T.J., Chinkuyu A., Dulaney W., Kaul M., and Daughtry C.S., 2004. Analysis of surrogate indicators for evidence of subsurface preferential flow pathways: impact of subsurface preferential flow on variability of NDVI. Proc. 2004 IEEE Int. Geoscience and Remote Sensing Symposium, IGARSS'04, 6, 3992-3995. https://doi.org/10.1109/igarss.2004.1370003

Yoder R.E., Freeland R.S., Ammons J.T., and Leonard L.L., 2001. Mapping agricultural fields with GPR and EMI to identify offsite movement of agrochemicals. J. Appl. Geophysics, 47(3), 251-259. https://doi.org/10.1016/s0926-9851(01)00069-6

Zhang J., Lin H., and Doolittle J., 2014. Soil layering and preferential flow impacts on seasonal changes of GPR signals in two contrasting soils. Geoderma, 213, 560-569. https://doi.org/10.1016/j.geoderma.2013.08.035

Zhu Q., and Lin H.S., 2009. Simulation and validation of concentrated subsurface lateral flow paths in an agricultural landscape. Hydrol. Earth System Sci., 13(8), 1503-1518. https://doi.org/10.5194/hess-13-1503-2009

Zipper S.C., Soylu M.E., Booth E.G., and Loheide S.P., 2015. Untangling the effects of shallow groundwater and soil texture as drivers of subfield-scale yield variability. Water Resour. Res., 51(8), 6338-6358. https://doi.org/10.1002/2015WR017522 